\title{
Knowledge, attitude and practice towards salt intake and health among non-academic staff of Universiti Kebangsaan Malaysia: A pilot study
}

\author{
Munirah Ismail ${ }^{1}$, Tuneesha Regu ${ }^{2}$, Martha James Jimponey ${ }^{3}$, Viola Michael ${ }^{1}$ \\ Fathimah Nestha Mohamed ${ }^{2}$, Rohana Hussin ${ }^{1}$ and Arimi Fitri Mat Ludin ${ }^{1, *}$ \\ ${ }^{1}$ Centre for Healthy Ageing and Wellness (H-CARE), Faculty of Health Sciences, Universiti \\ Kebangsaan Malaysia, Jalan Raja Muda Abdul Aziz, 50300 Kuala Lumpur, Malaysia. \\ ${ }^{2}$ Center for Community Health (ReaCH), Faculty of Health Sciences, Universiti Kebangsaan \\ Malaysia, Jalan Raja Muda Abdul Aziz, 50300 Kuala Lumpur, Malaysia. \\ ${ }^{3}$ Center for Toxicology and Health Risk (CORE), Faculty of Health Sciences, Universiti Kebangsaan \\ Malaysia, Jalan Raja Muda Abdul Aziz, 50300 Kuala Lumpur, Malaysia.
}

\section{ABSTRACT}

Background: Over the years, global salt intake has increased and has resulted in the escalation of cardiovascular diseases and hypertension. The lack of knowledge, as well as poor attitude and practice, are the main reasons that have led to high salt intake. Therefore, this study aims to evaluate the knowledge, attitude and practice (KAP) towards salt intake and health among non-academic staff of the Faculty of Health Sciences (FSK), Universiti Kebangsaan Malaysia (UKM). Methodology: This cross-sectional study was conducted among the non-academic staff of the Faculty of Health Sciences (FSK), Universiti Kebangsaan Malaysia (UKM). The respondents were recruited using stratified random sampling technique with an informed consent. A validated questionnaire to test the knowledge, attitude and practice (KAP) towards salt intake and health by the Ministry of Health Malaysia was converted into a Google form and the link was emailed to 118 participants. A total of 33 responses were obtained for evaluation. The significant values were set as $\mathrm{P}<0.05$. Results: It was observed that female participants had better attitudes towards salt intake and health compared to males $(p=0.044)$. Also, individuals with higher education levels had better attitudes towards salt intake and health, compared to those with lower education levels $(p=0.009)$. However, knowledge and practice of salt intake and health bore no significant results when considering gender, education level and age. Discussion and Conclusion: Overall, this study has identified sociodemographic characteristics as contributing factors towards individuals' attitude on salt intake and health. This may provide a crucial foundation in the development of cost-effective healthcare programs to widen knowledge, create awareness and promote a healthy lifestyle by reducing salt intake and further reduce the prevalence of non-communicable diseases.

* Correspondence Arimi Fitri Mat Ludin Centre for Healthy Ageing and Wellness (H-CARE), Faculty of Health Sciences, Universiti Kebangsaan Malaysia, Jalan Raja Muda Abdul Aziz, 50300 Kuala Lumpur, Malaysia. arimifitri@ukm.edu.my Tel: +603-9289 8043

Received: 30 November 2020 Revised: 18 February 2021 Accepted: 29 May 2021 Published: 3 June 2021

doi https://doi.org/10.28916/lsmb.5.1.2021.75
Keywords: Attitude; health; knowledge; practice; salt intake

\section{INTRODUCTION}

Numerous studies have linked excessive dietary salt (sodium) intake with multiple adverse health outcomes including hypertension, cardiovascular diseases, stroke (Brown et al., 2009), increased risk of gastric cancer (Tsugane, 2005), as well as indirectly causing obesity (Allison, 2018). In Malaysia, the overall prevalence of hypertension amongst adults is $30 \%$, whilst cardiovascular diseases are the leading causes of death where hypertension is one of the major attributable risk (Institute for Public Health, 2020). Additionally, in 2014, $18.0 \%$ of the newly diagnosed renal failure patients requiring dialysis were associated with hypertension and this trend has been increasing since 2010 (National Renal Registry, 2014). 
As part of the strategy to reduce the global burden of noncommunicable diseases, the World Health Organisation (WHO) has recommended reducing salt intake to less than $5 \mathrm{~g}$ of salt per day $(2000$ $\mathrm{mg} /$ day of sodium) (WHO, 2010), a recommendation that Malaysia have adopted into their own salt intake guideline ( $\mathrm{MOH}, 2017)$. Nonetheless, despite the detrimental effects of excessive salt intake and numerous salt reduction campaigns, the population consumption of salt generally exceeds the stipulated recommendation. In 2010, the estimated level of global sodium intake was $3.95 \mathrm{~g} /$ day, and regionally the mean level ranged between $2.18-5.51 \mathrm{~g} /$ day (Mozaffarian et al., 2014). In Malaysia, the dietary trends for salt intake estimated using 24-hour urinary excretion were found to be at least $8.5 \mathrm{~g} / \mathrm{day}$ (Rashidah et al., 2014). On the other hand, the average sodium intake assessed using 24hour dietary recall was found to be lower at $1935 \mathrm{mg}$ /day (Institute for Public Health, 2014). The MySalt study reported a sodium intake of 2860 $\mathrm{mg}$ /day from 24-hour urine analysis and $3393 \mathrm{mg} /$ day from a food frequency questionnaire amongst staff in the Ministry of Health Malaysia (Institute for Public Health, 2016).

Various factors can determine the level of salt intake in a population. Of those factors, salt intake was thought to be influenced by an individual's knowledge, attitude and practice (KAP) towards salt intake and health (Mahat et al., 2017), while sociodemographic characteristics including gender, age and educational levels have been shown to influence individuals' KAP. A study in Australia found that women were more concerned about the amount of salt they consumed and hence were more likely to buy low salt food in comparison to men (Webster et al., 2010). A similar result was yielded in the study conducted in Lebanon which revealed that females are more knowledgeable, possess better attitude and practice in reducing salt in their diet by following dietary recommendations than males (Nasreddine et al., 2014). A urinary assessment to detect sodium excretion also observed that male participants excreted higher amounts of sodium (3226 mg/day) as compared to female participants (2621 $\mathrm{mg}$ /day) (Institute for Public Health, 2016). Overall, women were reported to be more health conscious than men concerning salt consumption (Dickson-Spillmann \& Siegrist, 2011; Webster et al., 2010). Thus, it is important to further explore gender differences in salt intake since most studies including the latest prevalence reports in Malaysia, have revealed that high consumption of salt among men as compared to women has led to the risk of getting hypertension: $33.7 \%$ male versus $31.6 \%$ female (Naing et al., 2016), death due to ischaemic heart disease: $17.3 \%$ males and $11.4 \%$ females and other chronic illnesses (Department of Statistics Malaysia, 2020).

According to the Australian Division of World Action on Salt and Health (AWASH) survey, it was reported that older people were more knowledgeable and aware of the negative effects of high amounts of salt and its impact on health (Webster et al., 2010). In addition, it was also found that when compared to younger individuals, older individuals were more likely to pay more attention to food labels before purchasing while shopping for food. Correspondingly, academic qualification was found to influence individuals' KAP on salt intake and health. According to the Institute for Public Health, although there is no statistical significance between education and salt consumption, individuals with higher academic qualification had slightly lesser amounts of sodium excretion during urinary assessment (Institute for Public Health, 2016). Secondary education students and below reported a high amount of sodium excretion of $2937 \mathrm{mg} /$ day compared to college or university candidates with $2903 \mathrm{mg} /$ day. Higher academic graduates have greater awareness of the adverse effects of high sodium intake on health and reported that they tended to avoid consuming processed food (Marakis et al., 2014). Moreover, these groups of graduates also stated that they frequently checked the food labeling before purchasing any food items.

Determining the level of KAP and its association with sociodemographic characteristics in the population is crucial to establish intervention strategies and policy on the reduction of sodium intake. Additionally, for individuals working in healthcare related fields in particular, it is very important to assess their awareness regarding salt intake and health as they have the responsibility to guide as well as to serve as an example for the public. However, there is hardly any research around KAP on salt intake and health among non-academic staff in the healthcare field. Hence, this study was conducted with the aim of investigating the differences in gender, education level and age with KAP on salt intake and health among non-academic staff of the Faculty of Health Sciences, UKM.

\section{METHODOLOGY}

This study employed a cross-sectional design. The sample population was the non-academic staff from the Faculty of Health Sciences (FSK), Universiti Kebangsaan Malaysia (UKM). A total of 118 non-academic staff were selected for this study based on sample size calculated using the formula for a known population size (Krejcie \& Morgan, 1970). Calculation was done with a significance level of $5 \%$, degree of accuracy of $5 \%$ and population size, $\mathrm{N}=142$ (male, $\mathrm{n}=42$; female, $n=76$ ). To ensure a fair representation from both genders, stratified random sampling was employed. A list of names of all nonacademic staff was obtained from the registrar's office, and then separated according to gender. Each name was then assigned a number. Selection of participants was done according to the assigned number generated using an online random number generator. Inclusion criteria included all non-academic staff currently working in the Faculty of Health Sciences (FSK), Universiti Kebangsaan Malaysia (UKM). Meanwhile, non-academic staff who were pregnant, diagnosed with medical conditions, were on special diets or under any dietary restrictions were not eligible to participate in this study. Additionally, those with characteristics that could affect participation, which includes major physical illness, sensory impairment, disability or high level of agitation were also excluded from the study.

The study complies with the Declaration of Helsinki with ethical approval from the research ethics committee of the National University of Malaysia (UKM): JEP-2020-524. Information about the study was given to the non-academic staff and written consents were obtained. A set of self-administered questionnaires to test the knowledge, attitude and practice (KAP) on salt intake and health developed and validated by World Health Organization (WHO); and adapted by the Ministry of Health, Malaysia (Institute for Public Health, 2016) was used in this study. This online survey was done via google form. The questionnaire consisted of four sections, namely: (A) health information, (B) personal information, (C) anthropometry information and (D) KAP towards salt intake and health. In the health information section, the participants were asked if they were currently pregnant, undergoing any treatment for specific diseases or on any special diets. For the personal information section, they were asked about their age, gender and level of education. Participants were then required to selfreport their body weight, height and estimated waist circumference in the anthropometry section. In section D, participants were required to answer 8 questions with regards to KAP on salt intake and health as shown in Table 1. Both the English and Malay versions of the questionnaire were converted into a Google form format and the links were emailed to the participants.

\section{Statistical Analysis}

The IBM SPSS Statistics version 23 was used to carry out statistical analysis. The Fisher's exact test was used to determine the differences in proportions of knowledge levels among participants, based on gender and education level. As for comparison between participants' attitude and their sociodemographic characteristics, the Mann-Whitney $U$ test was used due to the violation of normality assumption. Independent sample t-test was performed to compare between participants' practice and sociodemographic characteristics. Lastly, correlation analyses were conducted using the Spearman correlation to determine the association between education level and participants' attitude while the Kendall's tau-b test was used to determine the relationship between age and attitude or practice due to the violation of normality and linearity assumptions. 
Table 1: KAP questionnaire

\begin{tabular}{clcl}
\hline Section & Content & Number of Questions & Scoring \\
\hline A & Health Information & 3 & \\
\hline B & Personal Information & 3 & \\
\hline C & Anthropometry Information & 3 & Given categorical scores where \\
& \multirow{2}{*}{ Knowledge } & 2 & $\begin{array}{l}\text { - was coded for correct answers } \\
\text { - was coded for wrong answers }\end{array}$ \\
\cline { 2 - 4 } & Attitude & & $\begin{array}{l}\text { Given continuous score with a maximum } \\
\text { score of 8 }\end{array}$ \\
\cline { 2 - 4 } & Practice $^{*}$ & 2 & $\begin{array}{l}\text { Given continuous score with maximum a } \\
\text { score of 18 }\end{array}$ \\
\hline
\end{tabular}

* Each answer is assigned a score of either $0,1,2,3,4$, or 5 except for question D8 on the practice domain where each answer selected by a participant was given 1 mark.

Table 2: Demographic and anthropometric data of participants

\begin{tabular}{|c|c|c|}
\hline \multirow{2}{*}{ Characteristics } & Frequency & Percentage \\
\hline & $(n=33)$ & $(\%)$ \\
\hline \multicolumn{3}{|l|}{ Gender } \\
\hline Female & 26 & 78.8 \\
\hline Male & 7 & 21.1 \\
\hline \multicolumn{3}{|l|}{ Age Group } \\
\hline$\leq 35$ years old & 21 & 63.6 \\
\hline$>35$ years old & 12 & 36.4 \\
\hline \multicolumn{3}{|l|}{ Education Level } \\
\hline Master's degree & 3 & 9.1 \\
\hline Bachelor degree & 14 & 42.4 \\
\hline STPM/Diploma/Certificate & 13 & 39.4 \\
\hline SPM & 3 & 9.1 \\
\hline \multicolumn{3}{|l|}{ BMI Classification $\left(\mathrm{kg} / \mathrm{m}^{2}\right)$} \\
\hline Normal weight (BMI $18.5-24.9$ ) & 12 & 36.4 \\
\hline Pre-Obesity (BMI 25.0 - 29.9) & 14 & 42.2 \\
\hline Obesity $(\mathrm{BMI}>30.0)$ & 7 & 21.2 \\
\hline \multicolumn{3}{|l|}{ Waist Circumference (WC) } \\
\hline \multicolumn{3}{|l|}{ Male } \\
\hline $\operatorname{Normal}(<102 \mathrm{~cm})$ & 7 & 21.2 \\
\hline $\operatorname{High}(>102 \mathrm{~cm})$ & 0 & 0 \\
\hline \multicolumn{3}{|l|}{ Female } \\
\hline $\operatorname{Normal}(<88 \mathrm{~cm})$ & 22 & 66.7 \\
\hline $\operatorname{High}(>88 \mathrm{~cm})$ & 4 & 12.1 \\
\hline
\end{tabular}

For all statistical analyses, the significant values were set at $\mathrm{p}<0.05$.

\section{RESULTS}

\section{Demographic data}

Among the 118 targeted participants, 10 (8.47\%) were not eligible and $75(63.55 \%)$ did not respond to the survey (google form questionnaire) sent to them. The final number of participants were 33 with a response rate of $37.28 \%$. Out of the 33 participants; 26 were females $(78.8 \%)$ and 7 were males $(21.1 \%)$. The majority of the participants were below 30 years old $(63.6 \%)$ with a bachelor degree (42.4\%). Aside from that, most of the participants had a body mass index (BMI) of more than $25 \mathrm{~kg} / \mathrm{m}^{2}(63.4 \%)$, although their waist circumference fell within the normal range (87.9\%). The demographic and anthropometric data of the participants are summarised in Table 2.

\section{Knowledge, attitude and practice (KAP)}

Table 3 summarises the knowledge, attitude and practice (KAP) towards salt intake and health among participants. In the knowledge domain, 32 participants (97\%) knew that a high salt diet may lead to serious health problems. These participants also knew that the serious health problem related to a high salt diet is high blood pressure. For attitudes, more than half of the participants (57.6\%) perceived that they consumed just the right amount of salt with $61.5 \%$ women and $43 \%$ men. Most female participants (65.4\%) believed that it is very important to reduce their salt intake, however majority of the male participants (71.4\%) believed that it is only somewhat important to reduce salt intake in their diet. Whilst for the practice domain, $39.4 \%$ of the participants reported that they always added salt in their cooking, followed by $30.3 \%$ who often and $24.2 \%$ who sometimes added salt in their cooking. However, the majority of the participants $(78.8 \%)$ never added salt to the food at the table. Most the staff (66.6\%) claimed that they do something on a regular basis to control their salt intake. The most common practices for lowering salt intake are not adding salt on food served at the table $(60.6 \%)$, as well as avoiding or minimizing processed food consumption (45.5\%).

A comparison between the three KAP domains with sociodemographic characteristics of participants (gender and education level) are summarised in Table 4. In the knowledge domain, there is no statistical significance between gender and the knowledge on the effect of a high salt diet towards health $(p=1.000)$. However, a Phi value, $\phi=$ -0.092 indicates a very small association between gender and knowledge. Similar findings were found when the participants' education levels were compared to knowledge on the effect of a high salt diet towards health ( $p=0.485$, Phi value, $\phi=-0.182$ ). Contrarily in the attitude domain, the attitude score of female participants (mean rank $=18.71, \mathrm{n}=26$ ) was significantly higher than those of the male participants (mean rank = 10.64, $\mathrm{n}=7)$, ( $\mathrm{U}=46.50, p=0.044$, two-tailed $)$. This effect can be considered as "medium" $(\mathrm{r}=.35)$ according to Cohen's (1988) conventions. 
Table 3: Summary of knowledge, attitude and practice (KAP) towards salt intake and health among participants

\begin{tabular}{|c|c|c|c|c|c|c|c|c|c|c|c|c|}
\hline \multirow[b]{2}{*}{ KAP Questions } & \multirow{2}{*}{\multicolumn{2}{|c|}{$\begin{array}{l}\text { KAP } \\
\text { Answers }\end{array}$}} & \multirow[b]{2}{*}{$\begin{array}{c}\text { Total } \\
(\mathbf{n}=33)\end{array}$} & \multicolumn{2}{|c|}{ Gender } & \multicolumn{2}{|c|}{ Age (years) } & \multicolumn{2}{|c|}{ Education Level } & \multicolumn{3}{|c|}{ Body Mass Index (BMI) } \\
\hline & & & & Male & Female & $\leq 35$ & $>35$ & $\begin{array}{l}\text { Bachelor/ } \\
\text { Master }\end{array}$ & $\begin{array}{l}\text { SPM/STPM/ } \\
\text { Diploma/ } \\
\text { Certificate }\end{array}$ & Normal & Pre-Obesity & Obesity \\
\hline \multirow{5}{*}{$\begin{array}{l}\text { Q1. Do you add } \\
\text { salt to food at the } \\
\text { table? }\end{array}$} & A. & Never & $26(78.8 \%)$ & $4(57.1 \%)$ & $22(84.7 \%)$ & $17(81.0 \%)$ & $9(75.1 \%)$ & $15(88.2 \%)$ & $11(68.8 \%)$ & $10(83.4 \%)$ & $12(85.8 \%)$ & $4(57.1 \%)$ \\
\hline & & Rarely & $2(6.1 \%)$ & 0 & $2(7.7 \%)$ & $1(4.7 \%)$ & $1(8.3 \%)$ & $1(5.9 \%)$ & $1(6.2 \%)$ & $1(8.3 \%)$ & $1(7.1 \%)$ & 0 \\
\hline & & Sometimes & $4(12.1 \%)$ & $3(42.9 \%)$ & $1(3.8 \%)$ & $3(14.3 \%)$ & $1(8.3 \%)$ & $1(5.9 \%)$ & $3(18.8 \%)$ & 0 & $1(7.1 \%)$ & $3(42.9 \%)$ \\
\hline & D. & Often & $1(3.0 \%)$ & 0 & $1(3.8 \%)$ & 0 & $1(8.3 \%)$ & 0 & $1(6.2 \%)$ & $1(8.3 \%)$ & 0 & 0 \\
\hline & E. & Always & 0 & 0 & 0 & 0 & 0 & 0 & 0 & 0 & 0 & 0 \\
\hline \multirow{5}{*}{$\begin{array}{l}\text { Q2. In the food } \\
\text { you eat at home, } \\
\text { salt is added in } \\
\text { cooking. }\end{array}$} & & Never & 0 & 0 & 0 & 0 & 0 & 0 & 0 & 0 & 0 & 0 \\
\hline & & Rarely & $2(6.1 \%)$ & $1(14.3 \%)$ & $1(3.8 \%)$ & $2(9.5 \%)$ & 0 & $1(5.9 \%)$ & $1(6.2 \%)$ & $1(8.3 \%)$ & $1(7.2 \%)$ & 0 \\
\hline & & Sometimes & $8(24.2 \%)$ & $3(42.9 \%)$ & $5(19.2 \%)$ & $5(23.8 \%)$ & $3(25.0 \%)$ & $3(17.6 \%)$ & $5(31.3 \%)$ & $2(16.7 \%)$ & $3(21.4 \%)$ & $3(42.9 \%)$ \\
\hline & D. & Often & $10(30.3 \%)$ & $2(28.5 \%)$ & $8(30.8 \%)$ & $5(23.8 \%)$ & $5(41.7 \%)$ & $6(35.3 \%)$ & $4(25.0 \%)$ & $4(33.3 \%)$ & $3(21.4 \%)$ & $3(42.9 \%)$ \\
\hline & E. & Always & $13(39.4 \%)$ & $1(14.3 \%)$ & $12(46.2 \%)$ & $9(42.9 \%)$ & $4(33.3 \%)$ & $7(41.2 \%)$ & $6(37.5 \%)$ & $5(41.7 \%)$ & $7(50.0 \%)$ & $1(14.2 \%)$ \\
\hline \multirow{6}{*}{$\begin{array}{l}\text { Q3. How much } \\
\text { salt do you think } \\
\text { you consume? }\end{array}$} & & Far too much & 0 & 0 & 0 & 0 & 0 & 0 & 0 & 0 & 0 & 0 \\
\hline & & Too much & $8(24.2 \%)$ & $2(28.5 \%)$ & $6(23.2 \%)$ & $4(19.0 \%)$ & $4(33.3 \%)$ & $4(23.5 \%)$ & $4(25.0 \%)$ & $2(16.7 \%)$ & $3(21.5 \%)$ & $3(42.8 \%)$ \\
\hline & & Just right & $19(57.6 \%)$ & $3(43.0 \%)$ & $16(61.5 \%)$ & $14(66.7 \%)$ & $5(41.7 \%)$ & $13(76.5 \%)$ & $6(37.5 \%)$ & $9(75.0 \%)$ & $8(57.2 \%)$ & $2(28.6 \%)$ \\
\hline & & Too little & $1(3.0 \%)$ & 0 & $1(3.8 \%)$ & $1(4.8 \%)$ & 0 & 0 & $1(6.2 \%)$ & 0 & $1(7.1 \%)$ & 0 \\
\hline & & Far too little & $2(6.1 \%)$ & 0 & $2(7.7 \%)$ & 0 & $2(16.7 \%)$ & 0 & $2(12.5 \%)$ & $1(8.3 \%)$ & $1(7.1 \%)$ & 0 \\
\hline & & Don't know & $3(9.1 \%)$ & $2(28.5 \%)$ & $1(3.8 \%)$ & $2(9.5 \%)$ & $1(8.3 \%)$ & 0 & $3(18.8 \%)$ & 0 & $1(7.1 \%)$ & $2(28.6 \%)$ \\
\hline \multirow{3}{*}{$\begin{array}{l}\text { Q4. Do you think } \\
\text { that a high salt } \\
\text { diet could cause } \\
\text { serious health } \\
\text { problems? }\end{array}$} & A. & Yes & $32(97.0 \%)$ & $7(100 \%)$ & 25 (96.2\%) & $21(100 \%)$ & $11(91.7 \%)$ & $17(100 \%)$ & $15(93.8 \%)$ & $11(91.7 \%)$ & $14(100 \%)$ & $7(100 \%)$ \\
\hline & & No & 0 & 0 & 0 & 0 & 0 & 0 & 0 & 0 & 0 & 0 \\
\hline & C. & Don't know & $1(3.0 \%)$ & 0 & $1(3.8 \%)$ & 0 & $1(8.3 \%)$ & 0 & $1(6.2 \%)$ & $1(8.3 \%)$ & 0 & 0 \\
\hline \multirow{6}{*}{$\begin{array}{l}\text { Q5. If yes, what } \\
\text { sort of problem? }\end{array}$} & A. & High blood pressure & $32(97.0 \%)$ & $7(100 \%)$ & $25(96.2 \%)$ & $21(100 \%)$ & $11(91.7 \%)$ & $17(100 \%)$ & $15(93.8 \%)$ & $11(91.7 \%)$ & $14(100 \%)$ & $17(100 \%)$ \\
\hline & & Osteoporosis & 0 & 0 & 0 & 0 & 0 & 0 & 0 & 0 & 0 & 0 \\
\hline & & Stomach cancer & 0 & 0 & 0 & 0 & 0 & 0 & 0 & 0 & 0 & 0 \\
\hline & & None of the above & 0 & 0 & 0 & 0 & 0 & 0 & 0 & 0 & 0 & 0 \\
\hline & & All of the above & 0 & 0 & 0 & 0 & 0 & 0 & 0 & 0 & 0 & 0 \\
\hline & F. & Don't know & $1(3.0 \%)$ & 0 & $1(3.8 \%)$ & 0 & $1(8.3 \%)$ & 0 & $1(6.2 \%)$ & $1(8.3 \%)$ & 0 & 0 \\
\hline
\end{tabular}


Table 3: Summary of knowledge, attitude and practice (KAP) towards salt intake and health among participants (continued)

\begin{tabular}{|c|c|c|c|c|c|c|c|c|c|c|c|c|}
\hline Q6. How & A. & Not important & $1(3.0 \%)$ & 0 & $1(3.8 \%)$ & 0 & $1(8.3 \%)$ & 0 & $1(6.2 \%)$ & $1(8.3 \%)$ & 0 & 0 \\
\hline important to you & B. & Somewhat important & $13(39.4 \%)$ & $5(71.4 \%)$ & $8(30.8 \%)$ & $9(42.9 \%)$ & $7(58.4 \%)$ & $5(29.4 \%)$ & $8(50.0 \%)$ & $5(41.7 \%)$ & $5(35.7 \%)$ & $3(42.9 \%)$ \\
\hline $\begin{array}{l}\text { is lowering the } \\
\text { amount of } \\
\text { salt/sodium in } \\
\text { your diet? }\end{array}$ & C. & Very important & $19(57.6 \%)$ & $2(28.6 \%)$ & $17(65.4 \%)$ & $12(57.1 \%)$ & $4(33.3 \%)$ & $12(70.6 \%)$ & $7(43.8 \%)$ & $6(50.0 \%)$ & $9(64.3 \%)$ & $4(57.1 \%)$ \\
\hline Q7. Do you do & A. & Yes & $22(66.7 \%)$ & $2(28.6 \%)$ & $20(76.9 \%)$ & $16(76.2 \%)$ & $6(50.0 \%)$ & $13(76.5 \%)$ & $9(56.3 \%)$ & $8(66.7 \%)$ & $10(71.4 \%)$ & $4(57.2 \%)$ \\
\hline anything on a & B. & No & $9(27.3 \%)$ & $5(71.4 \%)$ & $4(15.4 \%)$ & $5(23.8 \%)$ & $4(33.3 \%)$ & $3(17.6 \%)$ & $6(37.5 \%)$ & $4(33.3 \%)$ & $3(21.4 \%)$ & $2(28.6 \%)$ \\
\hline $\begin{array}{l}\text { regular basis to } \\
\text { control your salt } \\
\text { or sodium intake? }\end{array}$ & C. & Don't know & $2(6.0 \%)$ & 0 & $2(7.7 \%)$ & 0 & $2(16.7 \%)$ & $1(5.9 \%)$ & $1(6.2 \%)$ & 0 & $1(7.2 \%)$ & $1(14.2 \%)$ \\
\hline \multirow[t]{6}{*}{$\begin{array}{l}\text { Q8. If yes, what do } \\
\text { you do? }\end{array}$} & A. & $\begin{array}{l}\text { Avoid/minimize } \\
\text { consumption of } \\
\text { processed food. }\end{array}$ & $15(45.5 \%)$ & $2(28.6 \%)$ & $13(50.0 \%)$ & $9(42.9 \%)$ & $6(50.0 \%)$ & $7(41.2 \%)$ & $8(50.0 \%)$ & $4(33.3 \%)$ & $8(57.2 \%)$ & $3(42.9 \%)$ \\
\hline & B. & $\begin{array}{l}\text { Look at the } \\
\text { salt/sodium labels on } \\
\text { food packaging. }\end{array}$ & $8(24.2 \%)$ & $1(14.3 \%)$ & $7(26.9 \%)$ & $5(23.8 \%)$ & $3(25.0 \%)$ & $4(23.5 \%)$ & $4(25.0 \%)$ & $2(16.7 \%)$ & $5(35.7 \%)$ & $1(14.2 \%)$ \\
\hline & C. & $\begin{array}{l}\text { Do not add salt on } \\
\text { food served at the } \\
\text { table. }\end{array}$ & $20(60.6 \%)$ & $2(28.6 \%)$ & $18(69.2 \%)$ & $11(52.4 \%)$ & $4(33.3 \%)$ & $8(47.1 \%)$ & $7(43.8 \%)$ & $4(33.3 \%)$ & $8(57.2 \%)$ & $3(42.9 \%)$ \\
\hline & D. & $\begin{array}{l}\text { Buy low salt } \\
\text { alternatives. }\end{array}$ & $8(24.2 \%)$ & 0 & $8(30.8 \%)$ & $4(19.0 \%)$ & $4(33.3 \%)$ & $4(23.5 \%)$ & $4(25.0 \%)$ & $2(16.7 \%)$ & $6(42.9 \%)$ & 0 \\
\hline & E. & $\begin{array}{l}\text { Do not add salt when } \\
\text { cooking. }\end{array}$ & $2(6.1 \%)$ & 0 & $2(7.7 \%)$ & $2(9.5 \%)$ & 0 & $1(5.9 \%)$ & $1(6.2 \%)$ & $1(8.3 \%)$ & $1(7.2 \%)$ & 0 \\
\hline & F. & $\begin{array}{l}\text { Use spices other than } \\
\text { salt when cooking. }\end{array}$ & $6(18.2 \%)$ & 0 & $6(23.1 \%)$ & $4(19.0 \%)$ & $2(16.7 \%)$ & $3(17.6 \%)$ & $3(18.8 \%)$ & 0 & $6(42.9 \%)$ & 0 \\
\hline
\end{tabular}

Table 4: Comparison between KAP domains and sociodemographic characteristics of participants

\begin{tabular}{|c|c|c|}
\hline \multirow{2}{*}{ KAP Domain } & \multicolumn{2}{|l|}{ p-value } \\
\hline & Gender & Educational Level \\
\hline Knowledge $\mathrm{a}^{\mathrm{a}}$ & 1.00 & 0.485 \\
\hline Attitude ${ }^{\mathrm{b}}$ & $0.044^{\star}$ & $0.009^{\star *}$ \\
\hline Practice $^{c}$ & 0.177 & 0.498 \\
\hline
\end{tabular}


Additionally, it was found that the attitude score of participants who have a Bachelor or Master's degree (mean rank $=21.15, \mathrm{n}=17$ ) was higher than participants who only have SPM, STPM, Diploma or Certificate qualification (mean rank $=12.59, \mathrm{n}=16$ ) with a significant difference between the two education level groups in relation to their attitude score ( $\mathrm{U}=65.50, p=0.009$, two-tailed). Nonetheless, based on Cohen (1988), this effect can be considered as "medium" $(r=.46)$. In order to further investigate the relationship between the attitude domain and educational levels, a bivariate Spearman's correlation coefficient $(\rho)$ was calculated and was found to be positive and strong, $[\mathrm{rs}(33)=.507, p$ $=0.003$.

As for the practice domain, no significant difference was observed between male and female participants in terms of their practices on salt intake $[t(31)=-1.38, p=0.177$, two-tailed, $\mathrm{d}=0.59,95 \% \mathrm{CI}$ of the mean difference $(-3.753,0.797)]$. It was also observed that participants' level of education is not statistically significant when compared to the practice domain $[\mathrm{t}(31)=.686, p=0.498$, two-tailed, $\mathrm{d}=0.29,95 \%$ CI of the mean difference $(-1.210,2.438)]$. Kendall's tau-b test indicated that the correlation between education level and practice scores was found to be very weak and positive ( $\tau=.145, p=0.317$, two-tailed, $n=33$ ). Similarly, a very weak and negative relationship was observed between age and attitude scores ( $\tau=-.024, p=0.859$, two-tailed, $\mathrm{n}=33$ ), as well as between age and practice scores $(\tau=-.110, p=0.403$, two-tailed, $\mathrm{n}=33$ ).

\section{DISCUSSION}

Dietary quality and dietary behaviors are ascribed to sociodemographic factors such as age (Hjartåker \& Lund, 1998), gender (Groth et al., 2001), and education (Kant \& Graubard, 2007; Parmenter et al., 2000), which fall under non-modifiable factors. Apart from these, social cognitive factors such as knowledge (Leganger \& Kraft, 2003), selfefficacy (Wardle \& Steptoe, 2003), attitudes, beliefs and practice (Institute for Public Health, 2014) are other contributing factors that are fortunately modifiable (Sarmugam et al., 2013). This study has explored the depth of knowledge and the type of attitude as well as practice (KAP) on salt intake and its effects on health in a group of non-academic staff from the Faculty of Health Sciences (FSK), Universiti Kebangsaan Malaysia (UKM). Specifically, this study aimed to investigate gender differences, education level and age with regards to KAP on salt intake and health in order to identify potential modifiable factors that may play a role in the development of salt intake reduction campaigns.

It was observed that gender plays a role in determining individuals' attitude towards salt intake and health. Women appear to have a better attitude in reducing salt from their diet as compared to men. This result is also in line with previous findings where the mean attitude score of female participants $(2.96 \pm 0.95)$ was significantly higher than men $(2.30$ \pm 1.48) (Nasreddine et al., 2014). Women are more knowledgeable, possess better attitude and practice in reducing salt in their diet by following dietary recommendations compared to their male counterparts. In general, women also have higher nutritional knowledge (Chourdakis et al., 2010; Hendrie et al., 2008; Parmenter et al., 2000) owing to an active interest in healthy eating and diet in comparison to men (Hearty et al., 2007; Tirodimos et al., 2009).

In another study conducted on KAP of salt intake and health in relation to gender differences, the majority of women in comparison to men stated that they mostly added salt during cooking but added less amount of salt at the table (Marakis et al., 2014). Moreover, women also perceive that the main contribution of high sodium is due to the salt added during cooking as compared to men. Although more than $50 \%$ of the participants lacked awareness on the maximum amount of sodium intake, more women than men reported that they were aware that there was a maximum amount of recommended salt intake by experts. In addition, women more than men believed that they were consuming the right amount or less than the required amount of salt. They also believe that it was crucial for them to take measures to reduce the amount of salt that they added to their daily diet. In terms of associating salt to health, in comparison to men, women were found to be more knowledgeable on the detrimental effects of high sodium intake that could lead to elevated blood pressure, obesity, stomach cancer and kidney stones. As for food labels, women were more likely to read the nutritional information on the food packaging prior to purchase and more than half of the women reported to check the sodium content per serving stated on the packaging.

Besides gender, the comparison and association between education level on attitude towards salt intake and health also revealed significant findings, whereby those with higher education showed better attitude than those with lower qualifications. These findings are similar to the study done in China among the Xuzhou residents in which individuals with higher education levels showed better attitude in salt reduction as opposed to those with lower education who had the tendency to add excessive amounts of salt due to lack of awareness with regards to high salt intake and health (Li et al., 2015). Furthermore, higher academic graduates have greater awareness of the adverse effect of high levels of sodium on health and reported that they tended to avoid consuming processed food (Marakis et al., 2014). Moreover, these groups of graduates also stated that they frequently checked the food labeling before purchasing any food items. It has been shown through various researches that people with higher educational levels are more likely to gain dietary-related information and implement this into their lifestyle (Parmenter et al., 2000). Hence, nutritional knowledge has been found to be higher in individuals with higher levels of education.

Contrary to the significant results observed in the attitude domain, the comparison and correlation related to the knowledge and practice domains showed insignificant results. This could be due to the small sample size of participants who voluntarily took part in this study. Nonetheless, this correlates to the results of a 24-hour urine assessment among the Malaysian Ministry of Health staff which revealed that there was no significant difference in the 24-hour urine sodium excretion between the age categories and education level although those who were older and those who had higher education excreted slightly lesser sodium (Institute for Public Health, 2016).

More importantly, this study has contributed to the scarcity of research done on KAP on salt intake and health among non-academic staff in the healthcare field. Since individuals in the healthcare fields have the responsibility to guide as well as to serve as an example to the public, it is crucial to further explore their levels of KAP on salt intake and health. Additionally, most studies focused on general health problems and the negative effects of salt, whilst this study focuses on KAP on salt intake and health whereby salt intake is found to be influenced by these factors (knowledge, attitude, practice). The result on gender differences and attitude towards salt intake and health as well as the comparison and association between education level and attitude towards salt intake and health yield significant results. This is an important finding which may serve as a foundation to construct interventional health programs focusing on ways to cater or cultivate positive attitudes among men with regards to salt intake. Moreover, significant results on education level and attitude shows that it is also vital to developed programs that will reach out to individuals with lower education levels.

However, there are limitations to this study, such as the low response rate of participants towards the emailed questionnaire which may have affected the findings. In addition, the study population is limited to only the non-academic staff in the Faculty of Health Sciences (UKM) who might have more exposure towards health-related information than the public. Thus, the result cannot be generalised to the public. Additionally, since the study was conducted as an online survey, the anthropometric measurements were self-reported by the participants and not measured by the researcher. This sort of selfreported measurement would lead to measurement bias. Therefore, we recommend that future studies should involve a bigger sample size to include all non-academic staff from all health-related faculties in UKM or even other universities. Also ideally anthropometric measurements should be conducted by the researcher to negate measurement bias. A comparison between KAP, dietary intake and sodium excretion among non-academic staff as well as general population may also yield a more robust result. 


\section{CONCLUSION}

This study highlights the importance of sociodemographic characteristics in relation to salt intake and health in which individuals' knowledge, attitude and practice of salt intake may affect their health. Regardless of the inability to generalize most of the findings due to an inadequate sample size, this study has the potential to provide insight in aiding health care programs focusing on salt intake reduction, since globally it has been found that sodium consumption has increased to an alarming level and has led to the escalation of diseases despite numerous campaigns being orchestrated to reduce salt intake.

\section{DISCLOSURES}

The authors declare no conflicts of interest in this work.

\section{ACKNOWLEDGEMENTS}

We wish to acknowledge our appreciation to Dr Ismarulyusda Ishak of Universiti Kebangsaan Malaysia (UKM) for her guidance in the statistical analysis. We also would like to thank the respondents for their participation in this study.

\section{REFERENCES}

Allison, S. J. (2018). High salt intake as a driver of obesity. Nature Reviews Nephrology, 14(5), 285-285.

https://doi.org/10.1038/nrneph.2018.23

Brown, I. J., Tzoulaki, I., Candeias, V., \& Elliott, P. (2009). Salt intakes around the world: implications for public health. International Journal of Epidemiology, 38(3), 791-813.

https://doi.org/10.1093/ije/dyp139

Chourdakis, M., Tzellos, T., Papazisis, G., Toulis, K., \& Kouvelas, D. (2010). Eating habits, health attitudes and obesity indices among medical students in northern Greece. Appetite, 55(3), 722-725. https://doi.org/10.1016/i.appet.2010.08.013

Department of Statistics Malaysia. (2020). Statistics on causes of death, Malaysia, 2020. Retrieved from

https://www.dosm.gov.my/v1/index.php? $\mathrm{r}=$ column/cthemeByCat $\&$ cat $=401$ \&bul id=QTU5T0dKQ1g4MHYxd3ZpMzhEMzdRdz09\&menu id=L0phe U43NWJwRWVSZklWdzQ4TlhUUT0

Dickson-Spillmann, M., \& Siegrist, M. (2011). Consumers' knowledge of healthy diets and its correlation with dietary behaviour. J Hum Nutr Diet, 24(1), 5460 . https://doi.org/10.1111/j.1365-277X.2010.01124.x

Groth, M. V., Fagt, S., \& Brøndsted, L. (2001). Social determinants of dietary habits in Denmark. Eur J Clin Nutr, 55(11), 959-966. https://doi.org/10.1038/sj.ejcn.1601251

Hearty, A. P., McCarthy, S. N., Kearney, J. M., \& Gibney, M. J. (2007). Relationship between attitudes towards healthy eating and dietary behaviour, lifestyle and demographic factors in a representative sample of Irish adults. Appetite, $48(1), 1-11$. https://doi.org/10.1016/j.appet.2006.03.329

Hendrie, G. A., Coveney, J., \& Cox, D. (2008). Exploring nutrition knowledge and the demographic variation in knowledge levels in an Australian community sample. Public Health Nutr, 11(12), 1365-1371. https://doi.org/10.1017/S1368980008003042

Hjartåker, A., \& Lund, E. (1998). Relationship between dietary habits, age, lifestyle, and socio-economic status among adult Norwegian women. The Norwegian Women and Cancer Study. Eur J Clin Nutr, 52(8), 565-572. https://doi.org/10.1038/sj.ejcn.1600608

Institute for Public Health. (2014). National Health and Morbidity Survey 2014 : Malaysian Adult Nutrition Survey (MANS) Vol. II : Survey Findings National Health Institute, Ministry of Health. Retrieved from http://iku.moh.gov.my/images/IKU/Document/REPORT/NHMS2014MANS-VOLUME-2-SurveyFindings.pdf

Institute for Public Health. (2016). Determination of dietary sodium intake among the Ministry of Health staff 2015 (MySalt 2015). Ministry of Health. Retrieved from

\section{http://iku.moh.gov.my/images/IKU/Document/REPORT/MvSalt2016/MvSa} ltReport.pdf

Institute for Public Health. (2020). National Health and Morbidity Survey (NHMS) 2019: Non-communicable diseases, healthcare demand, and health literacyKey Findings. National Health Institut, Ministry of Health. Retrived from http://iptk.moh.gov.my/images/technical report/2020/4 Infographic Book et_NHMS_2019__English.pdf

Kant, A. K., \& Graubard, B. I. (2007). Secular trends in the association of socioeconomic position with self-reported dietary attributes and biomarkers in the US population: National Health and Nutrition Examination Survey (NHANES) 1971-1975 to NHANES 1999-2002. Public Health Nutr, 10(2), 158-167. https://doi.org/10.1017/S1368980007246749

Krejcie, R. V., \& Morgan, D. W. (1970). Determining sample size for research activities. Educational and Psychological Measurement, 30(3), 607-610. https://doi.org/10.1177/001316447003000308

Leganger, A., \& Kraft, P. (2003). Control constructs: Do they mediate the relation between educational attainment and health behaviour? Journal of Health Psychology, 8(3), 361-372. https://doi.org/10.1177/13591053030083006

Li, T., Qin, Y., Lou, P., Chang, G., Chen, P., Qiao, C., Zhang, P., \& Zhang, N. (2015). Salt Intake and Knowledge of Salt Intake in a Chinese Population: A Crosssectional Study. Intern Med, 5(2), 186 https://doi.org/10.4172/2165-8048.1000186

Mahat, D., Md Isa, Z., Mohd Tamil, A., Mahmood, M. I., Othman, F., \& Ambak, R. (2017). The association of knowledge, attitude and practice with 24 hours urinary sodium excretion among Malay healthcare staff in Malaysia. International Journal of Public Health Research 7(2), 860-870.

Marakis, G., Tsigarida, E., Mila, S., \& Panagiotakos, D. B. (2014). Knowledge, attitudes and behaviour of Greek adults towards salt consumption: a Hellenic Food Authority project. Public Health Nutr, 17(8), 1877-1893. https://doi.org/10.1017/S1368980013002255

MOH. (2017). Recommended Nutrient Intake for Malaysia: A Report of the Technical Working Group on Nutritional Guidelines. Ministry of Health Malaysia. Retrieved from

http://nutrition.moh.gov.my/wp-content/uploads/2017/05/FA-BukuRNI.pdf

Mozaffarian, D., Fahimi, S., Singh, G. M., Micha, R., Khatibzadeh, S., Engell, R. E., Lim, S., Danaei, G., Ezzati, M., \& Powles, J. (2014). Global sodium consumption and death from cardiovascular causes. New England Journal of Medicine, 371(7), 624-634. https://doi.org/10.1056/NEIMoa1304127

Naing, C., Yeoh, P. N., Wai, V. N., Win, N. N., Kuan, L. P., \& Aung, K. (2016). Hypertension in Malaysia: An analysis of trends from the National Surveys 1996 to 2011. Medicine (Baltimore), 95(2), e2417 https://doi.org/10.1097/MD.0000000000002417

Nasreddine, L., Akl, C., Al-Shaar, L., Almedawar, M. M., \& Isma'eel, H. (2014), Consumer knowledge, attitudes and salt-related behavior in the Middle-East: the case of Lebanon. Nutrients, 6(11), 5079-5102. https://doi.org/10.3390/nu6115079

National Renal Registry. (2014). 22nd Report of the Malaysian Dialysis and Transplant Registry 2014. Malaysian Society of Nephrology. Retrieved from https://www.msn.org.my/msn/Doc/PublicDoc PB/Publication/mdtr22nd/2 2nd_MDTR_2014.pdf

Parmenter, K., Waller, J., \& Wardle, J. (2000). Demographic variation in nutrition knowledge in England. Health Education Research, 15(2), 163-174. https://doi.org/10.1093/her/15.2.163

Rashidah, A., Yeo, P., Noor Ani, A., Muhammad Fadhli, M., Tahir, A., Feisul Idzwan, M., Ahmad Ali, Z., Suhaila, A., Azli, B., Viola, M., Ruhaya, S., \& Madihah, M. (2014). Sodium intake among normotensive health staff assessed by 24-hour urinary excretion: A cross-sectional study. Mal J Nutr, 20(3), 317-326.

Sarmugam, R., Worsley, A., \& Wang, W. (2013). An examination of the mediating role of salt knowledge and beliefs on the relationship between sociodemographic factors and discretionary salt use: a cross-sectional study. International Journal of Behavioral Nutrition and Physical Activity, 10(1), 25. https://doi.org/10.1186/1479-5868-10-25

Tirodimos, I., Georgouvia, I., Savvala, T. N., Karanika, E., \& Noukari, D. (2009). Healthy lifestyle habits among Greek university students: differences by sex and faculty of study. East Mediterr Health J, 15(3), 722-728. https://doi.org/10.26719/2009.15.3.722

Tsugane, S. (2005). Salt, salted food intake, and risk of gastric cancer: Epidemiologic evidence. Cancer Science, 96(1), 1-6. https://doi.org/10.1111/j.1349-7006.2005.00006.x

Wardle, J., \& Steptoe, A. (2003). Socioeconomic differences in attitudes and beliefs about healthy lifestyles. Journal of Epidemiology and Community Health, 57(6), 440-443. https://doi.org/10.1136/jech.57.6.440

Webster, J. L., Li, N., Dunford, E. K., Nowson, C. A., \& Neal, B. C. (2010). Consumer awareness and self-reported behaviours related to salt consumption in Australia. Asia Pac J Clin Nutr, 19(4), 550-554.

WHO. (2010). Regional Consultation on strategies to reduce salt intake. World Health Organization Regional Office for the Western Pacific. Retrieved from 
https://iris.wpro.who.int/bitstream/handle/10665.1/10631/RS 2010 GE 26 SIN_eng.pdf

\section{Citation:}

Ismail, M., Regu, T., Jimponey, M. J., Michael, V., Mohamed, F. N., Hussin, R., \& Mat Ludin, A. F. (2021). Knowledge, attitude and practice towards salt intake and health among non-academic staff of Universiti Kebangsaan Malaysia: A pilot study. Life Sciences, Medicine and Biomedicine, 5(10).

https://doi.org/10.28916/lsmb.5.1.2021.75

Copyright (c) 2021 by the Author(s). Life Sciences, Medicine and Biomedicine (ISSN: 2600-7207) Published by Biome Journals - Biome Scientia Sdn Bhd. Attribution 4.0 International (CC BY 4.0). This open access article is distributed based on the terms and conditions of the Creative Commons Attribution license https://creativecommons.org/licenses/by/4.0/ 